\title{
Editorial
}

\section{Protecting Research Time to Improve Professional Leadership}

\author{
Herney Andrés García-Perdomo ${ }^{1}$ \\ ${ }^{1}$ Department of Surgery/Urology, School of Medicine, Universidad \\ del Valle, Cali, Colombia
}

Urol Colomb 2019;28:271-272.

Training in a surgical specialty has been focused on knowledge, caring for patients, obtaining procedural skills, and teaching, leading to little time to do research. Some of the surgeons and professors believe that this is the most important issue to cover since the most skilled surgeon will be the best expert in the chosen area. Nonetheless, some studies and statements have described a new era incoming for a surgical scientist. It might improve the performance in the area as long as the innovation and translation in the surgical specialty. ${ }^{1,2}$

The nature of the surgical training place surgeons /urologists in a relative disadvantage for academic success since fellowship programs grant the experience in research but not in the primary specialty training. ${ }^{3}$ In developed countries, physicians might obtain research training before starting their specialty training, and sometimes they are involved in the grant process and the opportunity to establish a research line with some mentors. However, this does not happen in non-developed countries. ${ }^{4}$

On the other side, many years ago, commercial companies started to control research in medicine, and financial support (from different parties) was minimal..$^{5}$ The effect of these elements influences the diminished number of physicians (surgeons) involved in research and the decline in surgical research. It mandates to train our future surgical scientists to enlighten the flame of research in our area. ${ }^{1}$

In this case, nurturing the academic career by protecting time for research might benefit from getting a successful professional life. Nowadays, young urologists face hypercompetitive academic scenario; therefore, it is of vital importance the protection of junior research from clinical, teaching, and administrative duties. Residents must have time to critically read and understand the published literature, attend methodology lectures, discuss with colleagues, perform and supervise field experiments, analyze data, manage administrative requirements, write compelling grant applications and write manuscripts, among many other essential research duties during their training. ${ }^{6}$

Having a protected time is vital

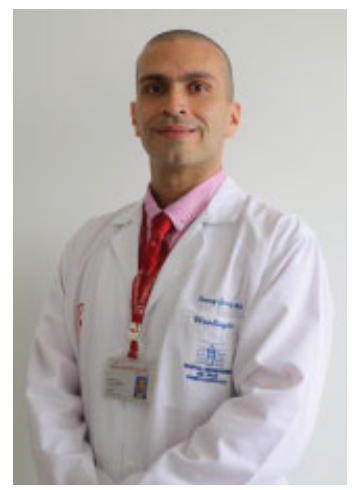

Doctor Herney Andrés GarcíaPerdomo, Editor in Chief of Revista Urología Colombiana for the resident and young urologist to explore academic interests such as: 1)Deciding whether research is impressive; 2) The kind of research (basic, translational, clinical or combination), 3) Getting a particular focus and 4) Learning new skills (technical and cognitive) to support the critical thinking in medicine and urology. ${ }^{2}$

The best way to start with this approach is as early as the academic program permits. It will offer the junior urologist to have better academic production for his/her curriculum vitae.

There are different interventions to set before starting a protected research time, for example, Identification of areas of interest, setting goals, identifying the available time, exploring the resources and strengths at the institution, knowing prospective mentors and collaborators, formulating a reachable research plan and pursuing national and international funds. ${ }^{2}$

There is no precise data to suggest how much protected time is adequate. Many institutions suggest 80:20 rule, representing $80 \%$ research time and $20 \%$ clinical, teaching, and administrative time. ${ }^{6}$ However, this does not comply with the real-world and surgical training in non-developed countries. Based on academic experience, I would suggest around $20 \%$ of research time. Nonetheless, this has to be validated.

As a conclusion, training in a surgical specialty, especially in urology must go from only focusing in caring of patients, to have protected research time to improve professional leadership in young urologist's careers and patient's outcomes. 


\section{References}

1 Suliburk JW, Kao LS, Kozar RA, Mercer DW. Training future surgical scientists: realities and recommendations. Ann Surg 2008;247(05):741-749

2 Singla N. The value of protecting research time during training. Eur Urol 2019;76(03):411-412

3 Ko CY, Whang EE, Longmire WP Jr, McFadden DW. Improving the Surgeon's participation in research: is It a problem of training or priority? J Surg Res 2000;91(01):5-8

4 Mann M, Tendulkar A, Birger N, Howard C, Ratcliffe MB. National institutes of health funding for surgical research. Ann Surg 2008; 247(02):217-221

5 Thompson JC. Seed corn. Impact of managed care on medical education and research. Ann Surg 1996;223(05):453-463

6 Barnard JA. Protected time: a vital ingredient for research career development. J Pediatr Gastroenterol Nutr 2015;60(03): 292-293 